\title{
Study on the Effect of Justice Perception in Performance Appraisal on Employee Performance
}

\author{
Shaoyan Peng ${ }^{a}$, Weidong Jiang \\ School of Economic and Management, Nanjing University of Science and Technology, Nanjing \\ 210094, China \\ aspeng@njust.edu.cn, ${ }^{b}$ njust0909@163.com
}

Keywords: justice perception in performance appraisal; employee performance; performance appraisal

Abstract: Justice perception in performance appraisal is an important criterion in judging the effectiveness of performance appraisal. However, previous academic research on justice perception in performance appraisal was mostly based on the mainstream three-dimensional model of organizational justice, and ignored the special context of performance appraisal. Based on the literature review, this paper explores the influence mechanism of justice perception in performance appraisal on employee performance and proposes some suggestions for improving the justice perception in performance appraisal of employee.

\section{Introduction}

Performance appraisal is an important module in the six traditional modules of enterprise human resource management. Effective performance appraisal can lead the development of the remaining modules of human resource management. All enterprises expect their performance appraisal system to objectively evaluate the true performance level of employees. So how should we judge the effectiveness of performance appraisal?

The research on performance appraisal has received much attention for nearly 100 years. However, previous research has focused on performance appraisal tools, the cognitive process of raters, reliability and validity, emotional factors in appraisal, and training for raters to improve the accuracy of the appraisal and reduce the error and such issues, while almost ignored the soft criteria of "ratee's response". In fact, when organizations conducting performance appraisal should pay more attention to the ratee's perception of the performance appraisal.

In 1967, American scholar Lawler[1] proposed a model for measuring the influence factors of effectiveness of performance appraisal. One of the variables named "Attitude toward fairness and acceptability of the evaluation system" plays an important role, which introduces justice perception into performance appraisal research. Landy, Barnes, and Murphy[2, 3] suggested that the perceived fairness and accuracy of performance appraisal was related to the frequency of evaluation, identification of goals, and the supervisor's knowledge of the performance and the job duties of the 
subordinate. Justice perception was thought to be an important mediator of the effectiveness of performance feedback as well as a possible source of job satisfaction, in and of itself. They described an examination of the hypothesis that perceptions of justice are affected by the level of previous performance rating; that is, employees who received high ratings would be more likely to describe the evaluation process as fair and accurate than those who received low ratings[3]. As research deepens, qualitative characteristics (justice and satisfaction) are also recognized as one of the main benchmarks of performance appraisal research.

Subsequently, more and more scholars have conducted research on the issues of justice perception in the context of performance appraisal. Among them, more attention has been paid to the dimensions and the effects of the justice perception in performance appraisal. This paper will comb and summarize related issues of justice perception in performance appraisal, as well as the effect of justice perception in performance appraisal on employee performance, and propose some suggestions for improving the justice perception in performance appraisal of employee.

\section{Justice Perception in Performance Appraisal}

Justice perception in performance appraisal is a branch of research on organizational justice. Therefore, most scholars use the dimension of organizational justice to define it. For example, Greenberg was one of the earliest scholars to introduce organizational justice into performance appraisal situations. He advocated the use of two-dimensional structure of organizational justice to define justice perception in performance appraisal, including procedural justice perception and distributive justice perception in performance appraisal. Palaiologos[4] used the three-dimensional structure of organizational justice to define the justice perception in performance appraisal. They suggested that distributive justice not only involves the impartiality of the distribution results obtained by individuals in the organization, but also relates to "decisions" or "fair content" after the end of the appraisal process. Whether these aspects make the ratees feel fair. They argued that procedural justice perception mainly refers to the perception of justice of the methods and mechanisms used to determine the appraisal results; interactional justice perception refers to the individual's perception of the manager's impartiality in their interpersonal relationship treatment and communication.

However, there are also some scholars who believe that the dimension of justice perception in performance appraisal should consider the specific situation of performance appraisal, that is, it should be different from the dimension of organizational justice.

For example, Greenberg[5] taked 217 middle managers in the United States as the research object, middle managers from three organizational samples responded to an open-ended questionnaire in which they described the determinants of particularly fair or unfair performance appraisals. By Qsort procedure, the responses were categorized and combined to yield seven distinct determinants of fairness in performance evaluations. Ratings of the perceived importance of these determinants were factor analyzed, revealing two distinct factors--procedural determinants and distributive determinants.

Erdogan[6] suggested that the specific situation of performance appraisal should not be neglected. She divided justice perception in performance appraisal into four dimensions: system procedural justice, rater procedural justice, distributive justice and interactional justice. That is to say, procedural justice is divided into system procedural justice and rater procedural justice. She suggested that the raters evaluate the ratees' performance according to the regulations of the evaluation system. Even if the organization establishes scientific and fair appraisal standards, if the raters do not implement these standards, the results of performance appraisal were unfair. Therefore, in the context of performance appraisal, the procedural justice of the two sources of organization and rater should be 
distinguished.

Chinese scholars Chen Lifen, Jiang Weidong [7] used the multi-focus analysis approach to classify the justice perception in performance appraisal into four dimensions: ratees' justice perception of appraisal system, ratees' justice perception of raters, ratees' justice perception of ratings, ratees' justice perception of related benefit according to the influencing factors of performance appraisal. They believe that the fair treatment of organizations and managers may cause employees to different degrees of attitude and behavior change. The structure of justice perception in performance appraisal should be studied from the perspectives of organizations and managers. These four dimensions all emphasize the ratees' own perception of justice perception in performance appraisal. The justice perception of appraisal system is the justice perception of the performance appraisal system formulated by the organization; the justice perception of related benefit is the justice perception of the decision making by the applicative performance appraisal result, such as salary adjustment, position adjustment, training, etc. The justice perception of raters refers to the justice perception of the process that the rater actually uses to evaluate ratees' performance; justice perception of ratings refers to the justice perception of the rating of performance appraisal they obtain.

This paper will follow Chen Lifen and Jiang Weidong' s ideas and divide the justice perception in performance appraisal into four dimensions: ratees' justice perception of appraisal system, ratees' justice perception of raters, ratees' justice perception of ratings, ratees' justice perception of related benefit, and explore their impact on employee performance.

\section{The Effect of Justice Perception in Performance Appraisal on Employee Performance}

Zapata et al[8] conducted two studies, the results showed that procedural justice predicted both self-reported and free-choice based measures of intrinsic motivation. Procedural justice also predicted task performance, a relationship that was partially mediated by intrinsic motivation. In contrast, interpersonal justice was not significantly related to either intrinsic motivation or task performance. Warokka et al[9]. have different opinions. After conducting empirical research, they found that the interactional justice has more influence than other types of organizational justice in evaluating employee's performance, which is contrary with previous researches. Employees are more concerned on interaction during and after the evaluation process. They are keen on knowing how they have been evaluated and what the feedback of their superior is after the performance appraisal process. It provides strong support for the relationship between employee perception of organizational justice in performance appraisal system and work performance. Ma Chao \& Lyu Zhengbao [10] studied the role of procedural justice perception in the process of performance appraisal, arguing that procedural justice perception affects performance appraisal satisfaction, performance improvement motives, changes in performance behavior, and organizational citizenship behavior. Zong Qianru [11] conducted research on several manufacturing companies in eastern China to explore the impact of justice perception in performance appraisal on employee performance. The result reveals that interactional justice and distributive justice have a direct impact on employee performance. Affective commitment plays the mediating role in the effect of procedural justice on employee performance.

According to the review, scholars paid little attention to empirical research on the effect of justice perception in performance appraisal on employee performance. However, based on existing research, it can be inferred that it has a positive effect on employee performance.

\subsection{The Effect of Procedural Justice Perception on Employee Performance}

Procedural justice perception refers to the employee's justice perception of the procedures that is 
used to make allocation decisions. In previous studies, some scholars have verified that procedural justice perception has a positive effect on employee performance. Colquitt et al[12] suggested that organizational trust plays an mediating role in the effect of justice on job performance, to explore these issues, they built and tested a more comprehensive model of trust mediation in which procedural, interpersonal, and distributive justice predicted affect- and cognition-based trust, with those trust forms predicting both exchange- and uncertainty-based mechanisms. The results of a field study in a hospital system revealed that the trust variables did indeed mediate the relationships between the organizational justice dimensions and job performance, with affect-based trust driving exchange-based mediation and cognition-based trust driving uncertainty-based mediation.

So we can infer procedural justice has a positive effect on employee performance. If employees believe that the results of performance appraisal do not meet their expectations, they may also accept this result as long as they perceive justice perception of the appraisal procedure. Therefore, the assumption that procedural justice perception has a positive effect on employee performance is reasonable, but the procedural justice perception under the specific context of performance appraisal needs to be divided to procedural justice perception of appraisal system and ratees' procedural justice perception of raters.

Erdogan[6]proposed theoretically that the procedural justice perception under the context of performance appraisal should be divided into system procedural justice and rater procedural justice. The design of the appraisal system theoretically guarantees the justice of the appraisal procedure, but the rater is the executor of the appraisal procedure and their appraisal result have a direct impact on the final performance results of the ratee. These two kinds of procedural justice perception may have different effects on employee performance. When verifying the impact of procedural justice perception on employee performance, the justice perception of appraisal system and ratees' procedural justice perception of raters should be differentiated.

Justice perception of appraisal system has a significant positive effect on employee performance. If the employees recognized the performance appraisal system that is designed by organization is scientific and professional, the employee will think that the appraisal system can effectively evaluate their true performance level and the appraisal results can reflect their real level of performance, then can perceived justice of the appraisal system.

The ratees' procedural justice perception of raters also has a significant positive effect on employee performance. The rater is the direct supervisor of the ratee, because the supervisor is the person who connects the organization and the employee at work, and also the mentor of the employee's work. Compared with organizations, supervisors and employees have closer psychological relationships, and they have a greater impact on employees. Therefore, the procedural justice perception of raters from the supervisory focus can effectively predict the employee's task performance. Employees' justice perceptions in performance appraisal are mostly derived from the appraisal procedures and appraisal methods used by supervisors, and whether the final appraisal results are fair and reasonable. When employees perceive that supervisors can fairly evaluate their performance, they think that supervisors give them full respect, then they will also work hard to actively promote their own performance, to create rewards for the organization to return this respect.

\subsection{The Effect of Distributive Justice Perception on Employee Performance}

Distributive justice perception refers to employees' justice perception of the organizational resource allocation results. However, the focus of employees on the results of performance appraisal is not only the level or grade of the appraisal, but is actually a concern for the related benefits after performance appraisal. These related benefit involve employee salary distribution, promotion opportunities, and training decisions. If employees think that the effort they make is not equal to the 
actual appraisal level or related benefits they obtained, it may affect their work enthusiasm and influence their future performance. Therefore, the distributive justice perception in the context of performance appraisal should be divided into ratees' justice perception of ratings and ratees' justice perception of related benefit, and they may also have an impact on employee performance. If the organization can provide employees with reasonable training opportunities, promotion opportunities, and opportunities for salary adjustment based on the results of performance appraisal, and the ratees' performance appraisal level that is determined by raters can reflect ratees' real work effort, that ratees will perceived justice perception of the distribution.

\section{Conclusion}

The four dimensions of justice perception in performance appraisal have a significant positive effect on employee performance. Therefore, in order to raise the overall performance level of employees and achieve the business objectives of the organization, the ratees' justice perception of appraisal system, ratees' justice perception of raters, rates' justice perception of ratings, ratees' justice perception of related benefit can be taken as the motivating factors of the employees.

So that the employees can obtain the organization and the supervisors' fair treatment, respect, concern, and recognition of value, and then arouse a perception of support and trust for supervisors and organizations, thereby improving job performance to ensure the achievement of business goals.

Organization can improve the procedural justice perception of appraisal system by following suggestions, such as performance appraisal system should fit the actual work of the employees and establishing a performance appraisal appeal channel; improve the distributive justice perception of related benefits by following suggestions, such as establishing a specific and reasonable performance-based pay system, rationally using performance appraisal results to allocate training opportunities for employees, and using performance appraisal results as a basis for employee position adjustments.

Therefore, in order to improve employees' justice perception of rater, the following suggestions are made for supervisors: to earnestly study the organization's performance appraisal system and consistently evaluate employee performance with the same organization's appraisal standards. In order to improve ratees' justice perception of ratings, the following suggestions are made for supervisors: to abandon solidified perceptions and stereotyped impressions, and view employee performance with developing perspectives, to provide performance feedback improving suggestions to employees.

\section{References}

[1] Lawler. 1967.The multitrait-multirater approach to measuring managerial job performance. Journal of Applied Psychology, Vol. 51 (5).

[2] Landy F J, Barnes J L, Murphy K R. 1978. Correlates of perceived fairness and accuracy of performance evaluation. Journal of Applied Psychology, Vol. 63(6).

[3] Landy F J, Barnesfarrell J L, Cleveland J N. 1980. Perceived fairness and accuracy of performance evaluation: A follow-up. Journal of Applied Psychology, Vol. 65(65).

[4] Palaiologos A, Papazekos P, Panayotopoulou L. 2011. Organizational justice and employee satisfaction in performance appraisal. Journal of European Industrial Training, Vol. 35(8).

[5] Greenberg J. 1986. Determinants of Perceived Fairness of Performance Evaluation. Journal of Applied Psychology, Vol. 71(2).

[6] Erdogan B. 2003. Antecedents and consequences of justice perceptions in performance appraisals. Human Resource Management Review, Vol.12(4).

[7] Chen Lifen, Jiang Weidong. 2014. Research on Justice perception in Performance Appraisal: Structure, Antecedents and Effects. Science Press.

[8] Zapataphelan C P, Colquitt J A, Scott B A, et al.2009. Procedural justice, interactional justice, and task performance: 
The mediating role of intrinsic motivation. Organizational Behavior \& Human Decision Processes, Vol. 108(1).

[9] Warokka A, Gallato C G, Thamendren, et al. 2012. Organizational Justice in Performance Appraisal System and Work Performance: Evidence from an Emerging Market. Journal of Human Resources Management Research.

[10] Ma Chao, Lyu Zhengbao. 2007. Procedural Justice and Its Role in Performance Evaluation. Journal of Shenyang Normal University Social Science Edition, Vol. 31(1).

[11] Zong Qianru, Wang Jinlong. 2013. Research on the Influence Mechanism of Fairness of Performance Appraisal on Job Performance. China Economist.

[12] Colquitt J A, Lepine J A, Piccolo R F, et al. 2012. Explaining the justice-performance relationship: trust as exchange deepener or trust as uncertainty reducer. Journal of Applied Psychology, Vol. 97(1). 